\title{
Molecule detected in formalin fixed tissue by antibodies MT1, DF-T1, and L60 (Leu-22) corresponds to CD43 antigen
}

\author{
W P STROSS, * R A WARNKE,§ D J FLAVELL, $\ddagger$ S U FLAVELL $\ddagger$ D SIMMONS, $\dagger$ \\ K C GATTER, * D Y MASON*
}

From the Nuffield Departments of ${ }^{*}$ Pathology and $\dagger$ Surgery, University of Oxford, John Radcliffe Hospital, Oxford, the $\ddagger$ Department of Pathology, Southampton General Hospital, Southampton, and the §Department of Pathology, Stanford University Medical Center, Stanford, California, USA

SUMmaRY Three monoclonal antibodies MT1, L60 (Leu-22), and DF-T1, were reported independently as recognising human $T$ cells in routinely processed, paraffin wax embedded tissue. The present study was performed to compare these three reagents in terms of their immunocytochemical reactions and target molecule(s). On Western blotting of white cell extracts the three antibodies reacted with antigens of the same molecular weight (range 110-160 kilodaltons). Furthermore, their immunocytochemical reactivity with normal human cells, as analysed by two-colour flow cytometry, was essentially identical (labelling of monocytes, most $\mathrm{T}$ lymphocytes, and weak reactions with some B cells), and the antibodies gave closely similar reactions on 54 white cell derived neoplasms. To identify the target antigen for these three reagents, antibodies from the Third International Workshop on Leucocyte Antigens were reviewed and it was shown that the Western blotting and immunocytochemical reactions of MT1, L60 (Leu-22), and DF-T1 were identical with those of the reagents which defined the CD43 antigen (also known as leucosialin or sialophorin). Furthermore, all these antibodies reacted with cells transfected with a cDNA clone encoding CD43.

It is concluded that antibodies MT1, L60 (Leu-22), and DF-T1 all recognise the heavily glycosylated myeloid/lymphoid associated CD43 antigen.

There has been much recent interest in monoclonal antibodies which detect fixation resistant antigens and which can be used to distinguish between $B$ and $T$ cell lymphomas in routinely processed paraffin wax sections. ${ }^{1}$ One widely used reagent of this sort is $\mathrm{MT}^{2}$ which recognises human $T$ cells and myeloid cells. Antibody L60 (Leu-22) ${ }^{34}$ shows some similarities in its reported reaction patterns, ${ }^{5}$ and recently a third anti-T cell antibody, DF-T1, has also been reported to work in fixed material (Flavell DJ, Flavell SV, Stross WP, Jones DB, Mason DY, Wright DH, unpublished observations). The molecular targets for these antibodies, however, have not been clearly defined ${ }^{6}$ and it is therefore unclear to what extent their reactions are comparable. This is useful information for the pathologist when deciding which antibodies to include in a routine phenotyping panel, or to exclude on the basis that they duplicate other reactions.

Accepted for publication 20 April 1989
This paper shows that MT1, DF-T1, and L60 (Leu22) recognise the same molecule and that the molecule defined by these antibodies is the CD43 antigen. ${ }^{7}$ This molecule (also known as sialophorin, ${ }^{8} \mathrm{gpL} 115,{ }^{9}$ leucosialin $^{10}$ and leucocyte sialoglycoprotein ${ }^{11}$ ) is defective in the Wiskott-Aldrich syndrome and may participate in $\mathrm{T}$ cell activation. ${ }^{12-14}$

\section{Material and methods}

DF-T1 was prepared in one of the authors' (DJF) laboratories. MT1 and L60 (Leu-22) were obtained from Euro-Diagnostics and Becton Dickinson, respectively. The CD43 antibodies G10-2, G19-1, and 84-3Cl were from the Third Workshop on Human Leucocyte Differentiation Antigens; other reagents were from Dako or one of the authors' laboratories (table 1).

Antibodies were isolated from ascitic fluid using a protein A sepharose column (Bioprocessing Consett) ${ }^{15}$ and conjugated to fluorescein isothiocyanate (FITC) 
Table 1 Antibodies used in this study

\begin{tabular}{llll}
\hline Specificity & Clone & Source & Form used \\
\hline CD2 (T11) & X53 & Author's laboratory & FITC-conjugate \\
CD3(T3) & T3-4B5 & DAKO & Supernate \\
CD4(T4) & T3-10 & DAKO & FITC-conjugate \\
CD5(T1) & DK23 & DAKO & Supernate \\
CD8 (T8) & DK25 & DAKO & FITC-conjugate \\
CD19(B4) & HD37 & Author's laboratory & FITC-conjugate \\
See text & DF-T1 & Author's laboratory & Supernate/ascitic \\
& MT1 & Euro-Diagnostics & Supernate \\
See text & MT1 & Ascitic fluid \\
See text & L60(Leu-22)Becton Dickinson & Ascitic fluid \\
CD43 & G10-2 & Ledbetter & Ascitic \\
CD43 & G19-1 & Ledbetter & Ascitic fluid \\
CD43 & 84-3C1 & Vilella & Ascitic fluid \\
\hline
\end{tabular}

isomer 1 (Sigma) at a protein concentration of $2 \mathrm{mg} /$ $\mathrm{ml}$, using $140 \mu \mathrm{g} \mathrm{FITC} / \mathrm{mg}$ of protein. Antibody DF$\mathrm{T} 1$, at a protein concentration of $2 \mathrm{mg} / \mathrm{ml}$, was conjugated to $\mathrm{N}$-hydroxysuccinimidobiotin (Sigma) dissolved in dimethyl sulphoxide $1 \mathrm{mg} / \mathrm{ml}(150 \mu \mathrm{g}$ of biotin/mg antibody).

\section{TISSUES AND CELLS Cell lines}

The HL60 promyelocytic cell line ${ }^{16}$ and the myeloblastic cell line $\mathrm{KG}^{17}$ were harvested in logarithmic growth phase. COS-7 cells ${ }^{18}$ were transfected with vector $\mathrm{CDM}^{19}$ alone, or with vector containing an insert (from a human placental cDNA library) that had been selected by a panning technique ${ }^{20}$ using the three CD43 antibodies from the Third Workshop. Cytospins of the transfected cells were fixed in acetone methanol 1:1 for one minute.

\section{Normal tissues}

A bone marrow aspirate was obtained from a patient with lymphoma who was in remission. Tonsils were obtained from routine tonsillectomies in the Ear, Nose and Throat Department, Radcliffe Infirmary, Oxford. Brain tissue was obtained at necropsy, and thymus from a child undergoing thoracotomy. Cryostat sections of $6 \mu \mathrm{m}$ thickness were fixed in acetone and stored, wrapped in foil at $-20^{\circ} \mathrm{C}$. Paraffin wax embedded sections were prepared using routine methods after fixation in formol saline.

\section{Lymphomas/leukaemias}

Blood smears were obtained from 15 cases of chronic lymphatic leukaemia (CLL).

Paraffin wax embedded sections were obtained from haematolymphoid neoplasms which had been phenotyped with a panel of antibodies in cryostat sections. Cases from the histopathology department of the John Radcliffe Hospital had been fixed in formol saline; cases from the department of pathology, Stanford University Medical Center had been fixed in 10\% neutral buffered formalin.
White cell extracts

Peripheral blood mononuclear cells were obtained from a normal subject by centrifugation over Lymphoprep (Nyegaard). Mononuclear cells were fractionated by centrifugation through Percol:1 sg 1.06 (Pharmacia). Lymphocytes and monocytes were more than $95 \%$ pure. Granulocytes were obtained from the resuspended cell pellets by sedimentation of erythrocytes with $4 \%$ Dextran 150 (BDH) in phosphate buffered saline (PBS). Cells were washed three times in PBS and $2 \times 10^{7}$ cells solubilised in $1 \mathrm{ml}$ of $0.5 \%$ Nonidet P40 (BDH) containing $1 \mathrm{mM}$ phenylmethyl-sulphonylfluoride (Sigma) and $20 \mathrm{mM}$ ethylene glyco-bis (amino ethyl ether) $\mathbf{N}, \mathbf{N}, \mathrm{N}^{\prime}, \mathrm{N}^{\prime}$-tetra acetic acid (Sigma).

\section{IMMUNOCYTOCHEMICAL ANALYSIS BY FLOW} CYTOMETRY

Cell suspensions

Unfractionated peripheral blood mononuclear cells and fresh tonsil cells in tissue culture medium (Gibco RPMI 1640) containing $10 \%$ fetal calf serum were separated on a density gradient as above. In each experiment negative controls were included: $(a)$ unstained cells; $(b)$ cells incubated with only the secondary antibody or phycoerythrin, or both.

\section{Single labelling}

A $50 \mu \mathrm{l}$ aliquot of cell suspension $\left(5 \times 10^{6} / \mathrm{ml}\right)$ was mixed with $50 \mu$ l primary antibody and incubated on ice for 30 minutes. The cells were washed twice and 50 $\mu$ l of FITC-conjugated rabbit anti-mouse $F\left(a^{\prime}\right)_{2}$ diluted $1 / 20$ (Dako) was addded. After incubation on ice for 30 minutes the cells were washed twice and fixed in $200 \mu \mathrm{l}$ of $1.5 \%$ formaldehyde in PBS.

\section{Double labelling}

Cells were incubated with two primary antibodies (conjugated to biotin or FITC) washed, incubated with streptavidin-phycoerythrin, and processed as above.

\section{Analysis}

Flow cytometry was performed with FACScan (Becton Dickinson). The relevant cell population was selected with live gates, and a minimum of 104 cells were analysed.

\section{IMMUNOENZYMATIC LABELLING OF TISSUE}

\section{SECTIONS AND CELLS}

Paraffin wax sections were dewaxed, hydrated, and incubated for $20-30$ minutes in $0.1 \%$ trypsin solution containing $0 \cdot 1 \%$ calcium chloride ( $\mathrm{pH} 7 \cdot 8)$. Tissue sections and cytospin slides were stained using an automated $^{21}$ alkaline phosphatase anti-alkaline phosphatase (APAAP) method. ${ }^{22}$ 


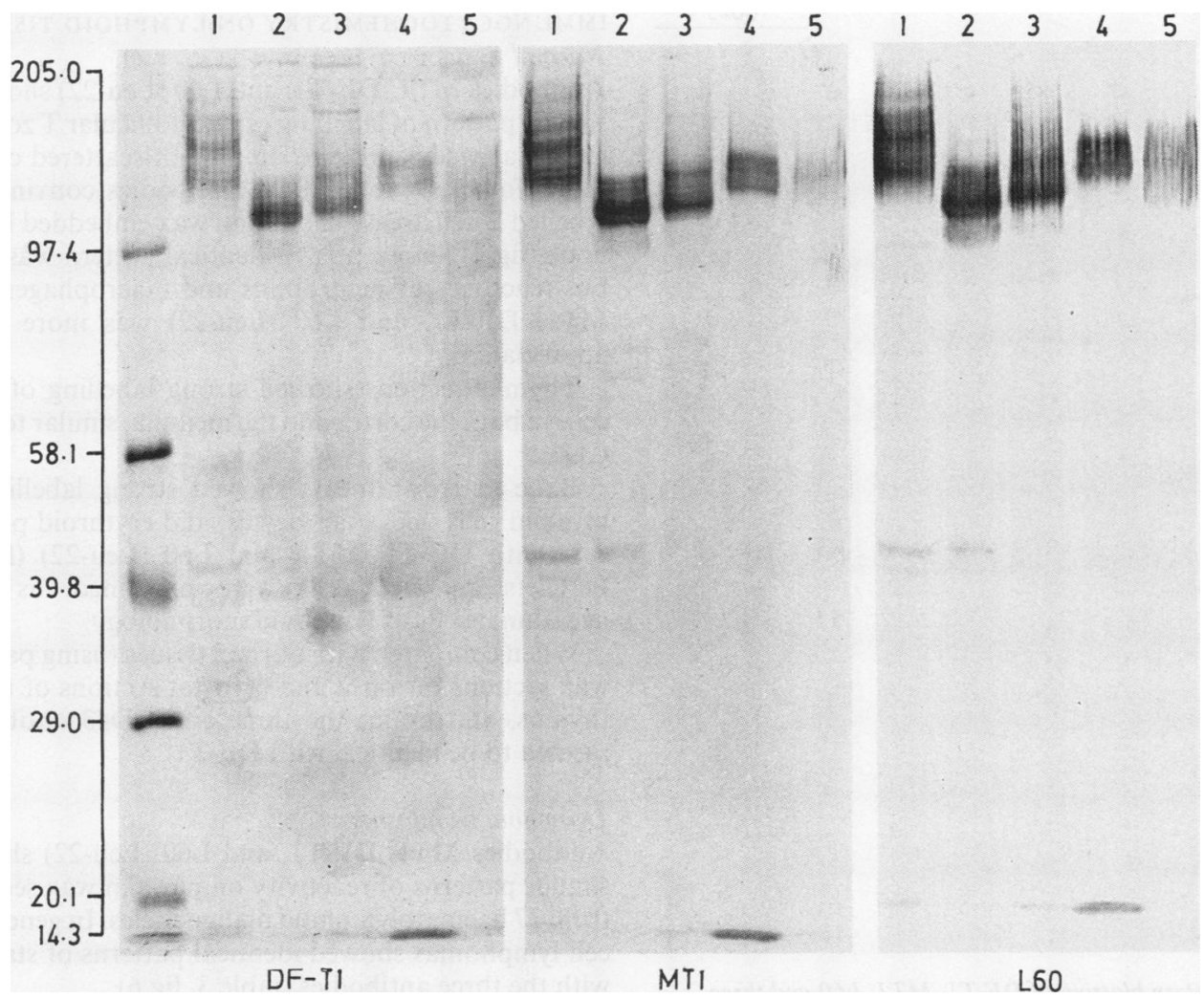

Fig 1 Western blotting of antibodies DF-T1, MT1, and L60 (Leu-22) performed in parallel with different white cell extracts. Track 1, HL60 cells; track 2, KG1 cells; track 3, lymphocytes; track 4, granulocytes; track 5, monocytes. Molecular weight standards are seen in the left hand track.

\section{WESTERN BLOTTING}

Lysates at a protein concentration of $1 \mathrm{mg} / \mathrm{ml}$ were separated by sodium dodecyl sulphate polyacryamide 961 electrophoresis (SDS-PAGE) on 5-15\% linear gradient gels under reducing conditions $\mathrm{s}^{23}$ with biotinylated molecular weight standards (Sigma). Separated components were electrophoretically transferred to nitrocellulose. ${ }^{24}$ Membranes were blocked with $1 \%$ bovine serum albumin (BSA) in $0.1 \mathrm{M}$ TRIShydrochloride buffer ( $\mathrm{pH} 7.6$ ), containing $0.1 \%$ Tween 20, and probed with monoclonal antibody. Bound antibody was detected using biotinylated goat anti-mouse immunoglobulins (Amersham) and the ABC immunoperoxidase system (Dako).

\section{Results}

\section{WESTERN BLOTTING}

Immunoblotting results obtained with DF-T1, MT1, and L60 (Leu-22) on five different white cell lysates are shown in fig 1 . The molecular weight heterogeneity of the antigen from different sources can be clearly seen as can the fact that the three antibodies gave identical blotting results. The apparent molecular weights are listed in table 2.

Western blots obtained with KG1 lysate using DFT1, MT1, L60 (Leu-22) and the three CD43 antibodies are shown in fig 2 . All six antibodies clearly identified a major band with an apparent molecular weight of 110

Table 2 Molecular weights of antigens extracted from different sources identified by DF-T1, MT1, and L60 (Leu-22)

\begin{tabular}{ll}
\hline Antigen source & Molecular weight (kilodaltons) \\
\hline HL60 cells & $130,140,150,160$ \\
KG1 cells & $95,110,120$ \\
Lymphocytes & 115,130 \\
Granulocytes & 130,135 \\
Monocytes & $110-150$ (smear) \\
\hline
\end{tabular}

Major bands are emboldened. 


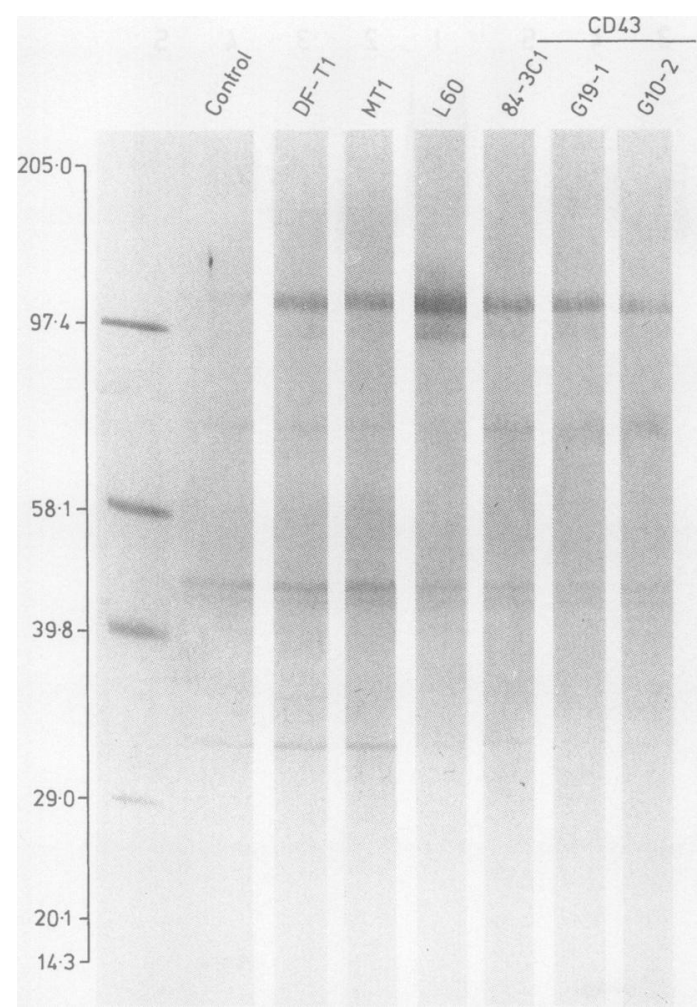

Fig 2 Western blotting of DF-T1,MT1, L60 and three CD43 antibodies performed on KG1 lysate showing that the six antibodies recognise molecules of the same molecular weight. Molecular weight standards are seen in the left hand track.

kilodaltons and a minor band at 95 kilodaltons, though the 95 kilodalton band was only weakly detected with antibodies DF-T1, MT1, 84-3C1, G19-1 and G10-2. In this instance L60 (Leu-22) was the only antibody to detect a weak band at 120 kilodaltons.

\section{FLOW CYTOMETRIC ANALYSIS}

Antibodies MT1, DF-T1, and L60 (Leu-22) and the three known anti-CD43 antibodies gave similar patterns of labelling when peripheral blood mononuclear cells were analysed, all monocytes and most lymphoid cells being positive. Double labelling showed that the DF-T1 positive lymphoid cells were $T$ cells (CD2, CD4, and CD8 positive, and negative with the B cell antigen CD19) (fig 3a).

There was a less clear distinction between positive and negative tonsil cells than had been obtained with blood leucocytes, but the results with the six antibodies were essentially identical. A small proportion $(7.6 \%)$ of B cells (CD19 positive cells) were stained, and a small proportion (8.9\%) of T cells (CD2 positive cells) were negative (fig $3 \mathrm{~b}$ ).

\section{IMMUNOCYTOCHEMISTRY ON LYMPHOID TISSUE \\ Normal tissues}

Antibodies MT1, DF-T1, and L60 (Leu-22) showed a similar pattern of labelling of interfollicular $\mathrm{T}$ zones in tonsils as well as intense staining of scattered cells in the B follicles. None of the antibodies convincingly labelled B cell areas. In paraffin wax embedded lymph node (fig 4) an essentially identical pattern was seen, but reactivity of neutrophils and macrophages with MT1, DF-T1, and L60 (Leu-22) was more easily appreciated.

Thymus sections showed strong labelling of most cells in both the cortex and the medulla, similar to antiCD3.

Bone marrow smears showed strong labelling of myeloid cells, megakaryocytes, and erythroid precursors with DF-T1, MT1, and L60 (Leu-22) (fig 5). Platelets and red cells were unstained, as were occasional cells of lymphoid morphology.

When compared with normal tissues (using paraffin wax sections of tonsil and cryostat sections of tonsil, thymus, and brain) the three anti-CD43 antibodies seemed to be identical with DF-T1.

\section{Lymphoid neoplasms}

Antibodies MT1, DF-T1, and L60 (Leu-22) showed similar patterns of reactivity on paraffin wax sections from 37 haematolymphoid malignancies. In general, $\mathrm{T}-$ cell lymphomas showed identical patterns of staining with the three antibodies (table 3, fig 6).

Reactivity of B cell tumours was most commonly

Table 3 Reactivity of DF-T1, MT1, and L60 (Leu-22) with haematolymphoid neoplasms in paraffin wax sections

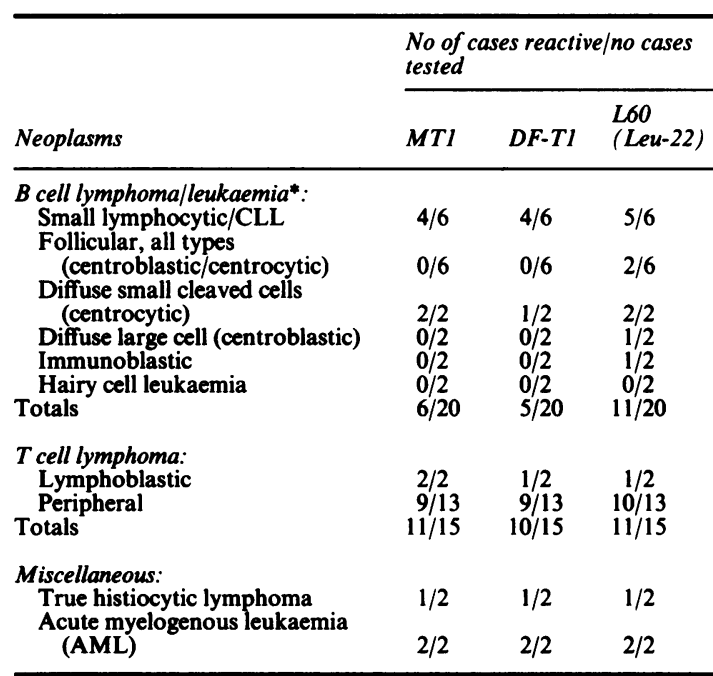

*B lymphomas are classified according to the Working Formulation with the Kiel classification in parentheses. 
(a)

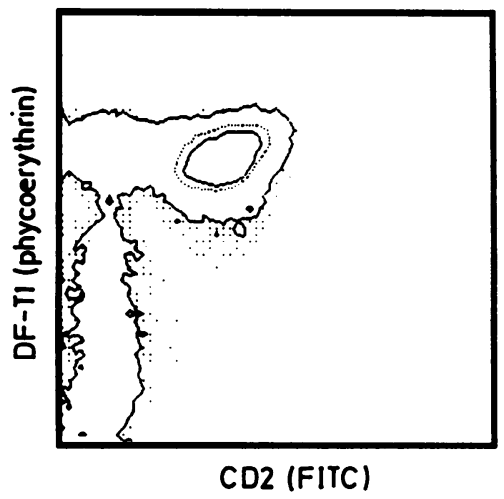

(a)

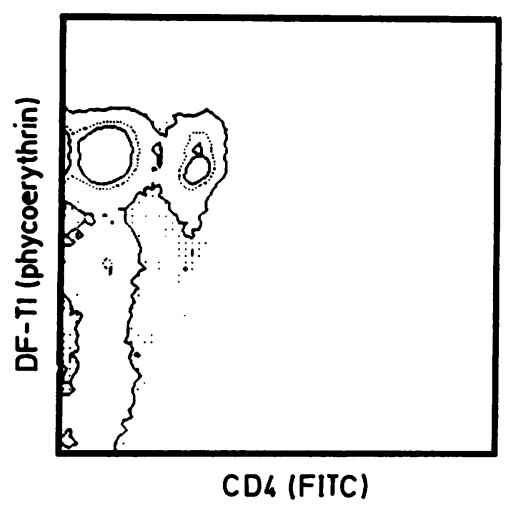

(b)

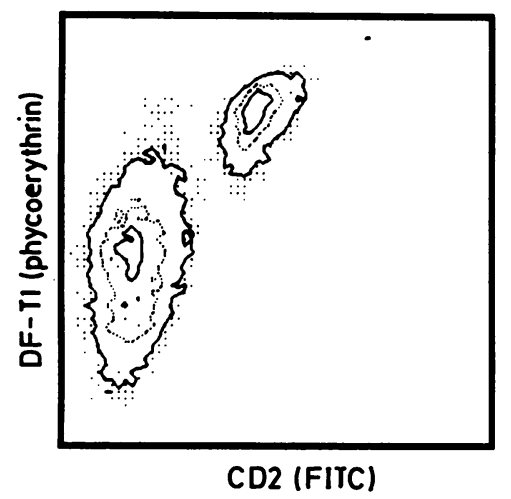

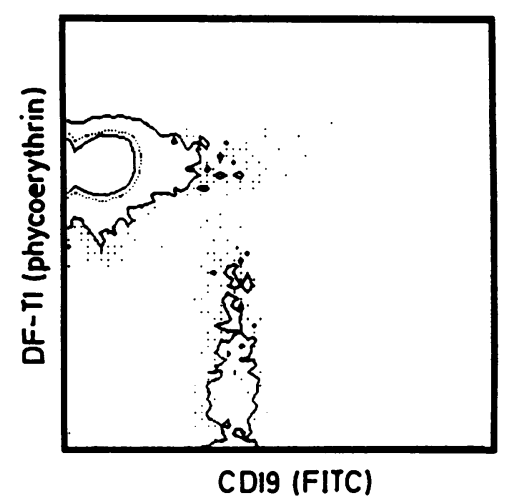
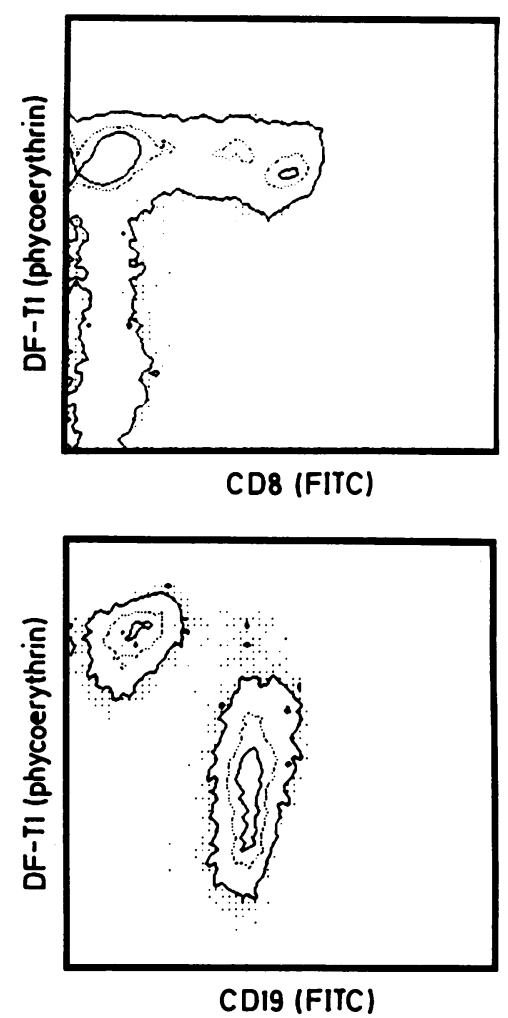

Fig 3 (a) Dual colour FACS analysis of peripheral blood lymphocytes with DF-T1 in combination with CD2, CD4, CD8 and CD19 (both axes log fuorescence intensity). (b) Dual colour FACS analysis of tonsil cell suspension with DF-TI in combination with $C D 2$ and CD19 (both axes log fluorescence intensity).

seen in diffuse small cell lymphomas/leukaemias (fig 7). A few of these positively labelled B cell tumours showed staining equal to that of the $T$ cell tumours but most were only weakly or focally stained. In the negative $B$ cell cases reactive $T$ cells, macrophages (fig 8), and epithelioid giant cells (fig 9) were stained. Some discrepancies in the reaction patterns of the three antibodies were observed (table 3) -that is, more B lymphomas and leukaemias were stained by L60 (Leu$22)$ than by MT1 and DF-T1 ( 11 of 20 cases compared with six and five cases, respectively). The labelling patterns of the antibodies on two histiocytic neoplasms and two cases of acute myeloid leukaemia (AML) were identical (table 3). 


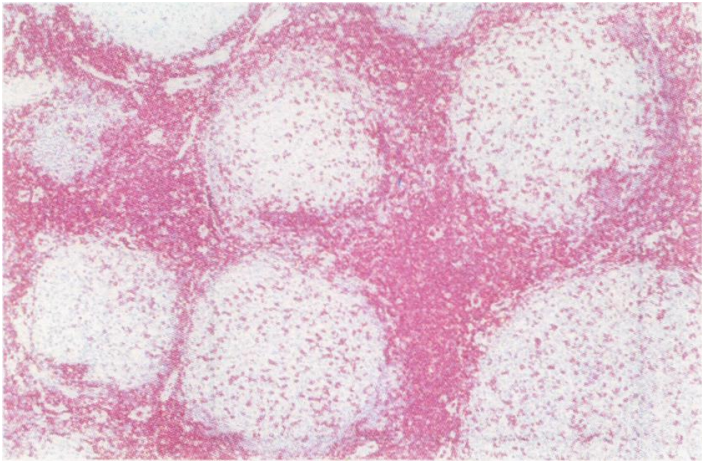

(4)

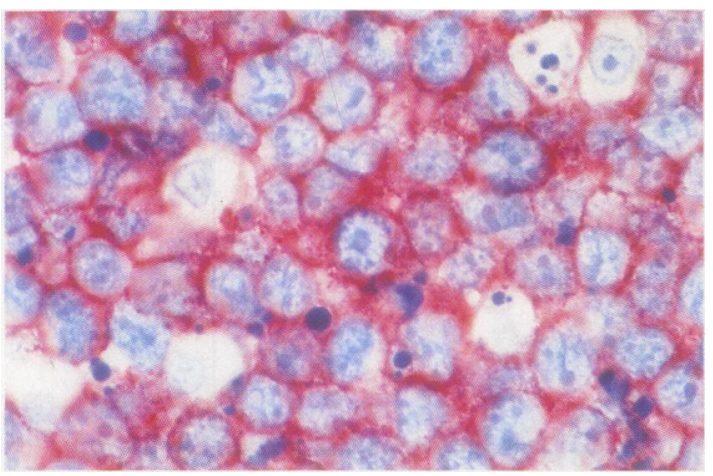

(6)

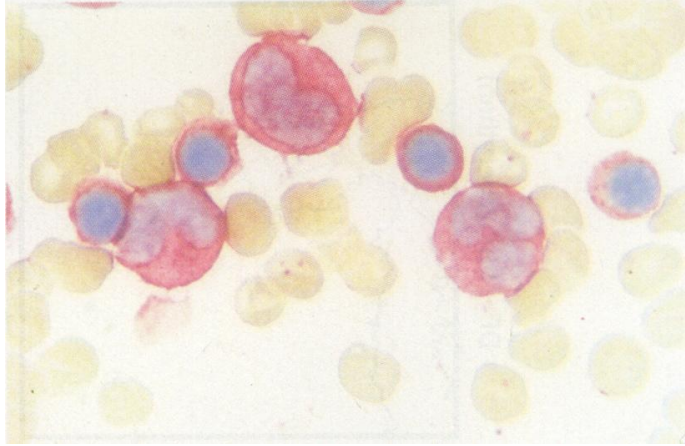

(5)

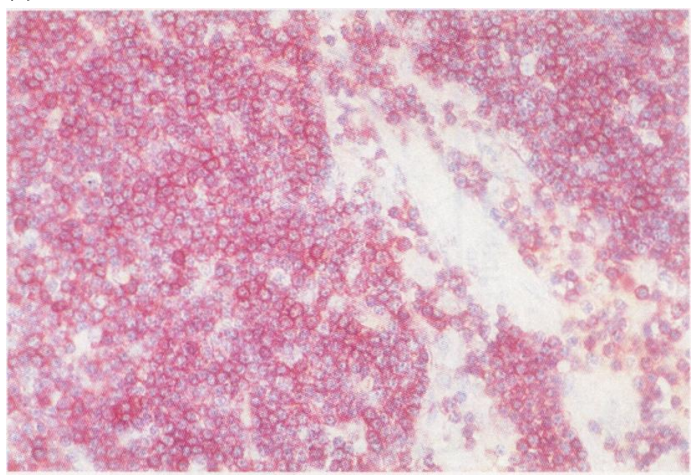

(7)

Fig 4 Normal lymph node paraffin wax section stained with DF-T1. Note strong staining of the $T$ cell areas and of scattered $T$ cells in the germinal centres.

Fig 5 Bone marrow smear stained with DF-T1. Three myeloid precursors and four normoblasts are strongly stained.

Fig 6 T cell non-Hodgkin's lymphoma staining strongly with DF-T1. Note strong uniform staining of all the tumour cells.

Fig 7 Section of lymph node containing B cell lymphocytic lymphoma. Note strong staining in this case with intensity equivalent to that seen in $T$ cell tumours.

\section{Smears}

In 11 of 15 cases of B cell CLL strong staining with DF-T1, MT1, and L60 (Leu-22) was seen (fig 10). The remaining four cases were negative for all three antibodies, granulocytes and monocytes providing an internal positive control. There was no correlation between the expression of CD5 (found in 12 of the 15 cases) and reactivity with DF-T1, MT1, and L60 (Leu22).

Table 4 Previously reported reactions of MT1 and L60 (Leu-22) on paraffin wax embedded white cell neoplasms

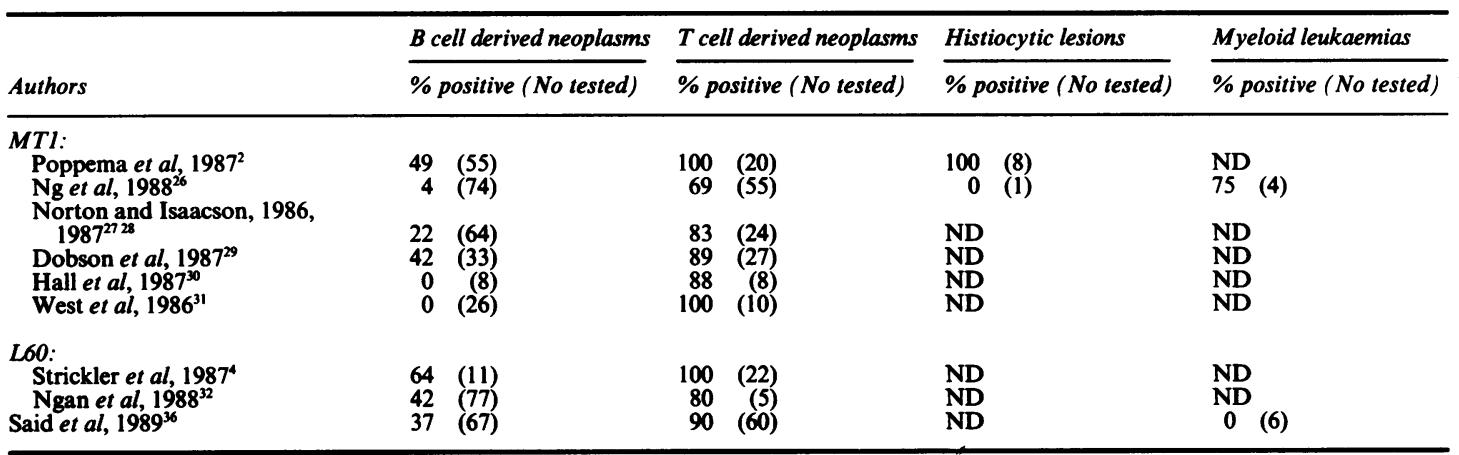

ND, no data. 


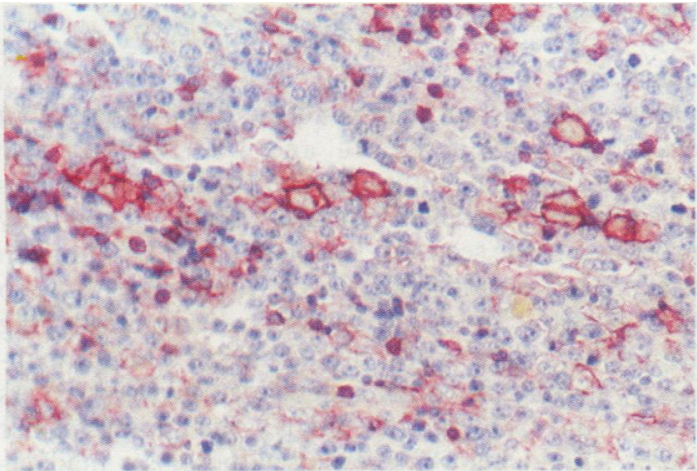

(8)

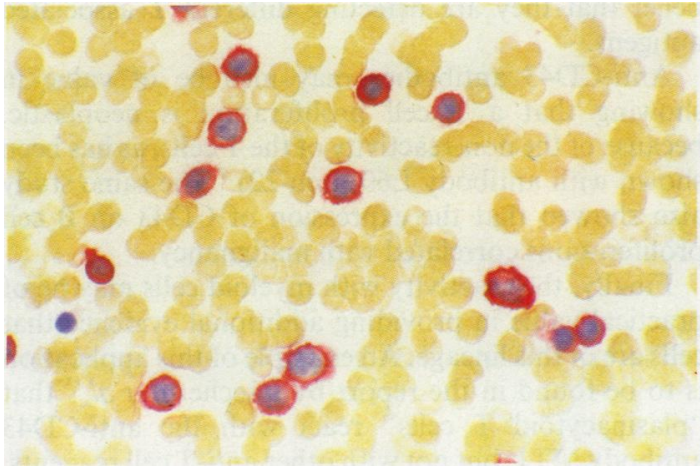

(10)

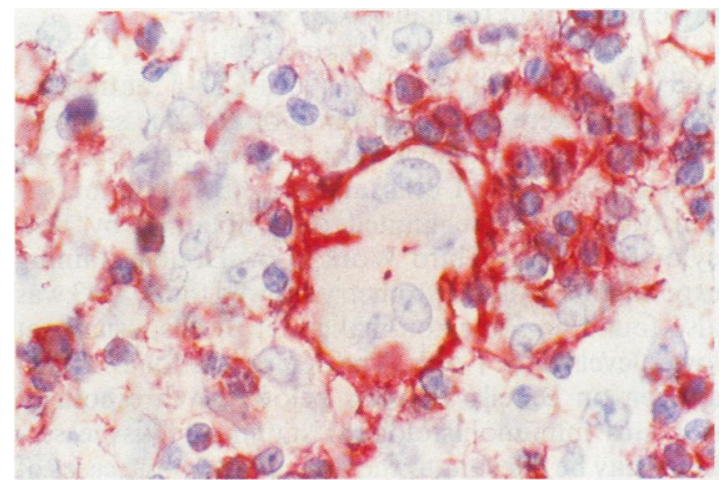

(9)

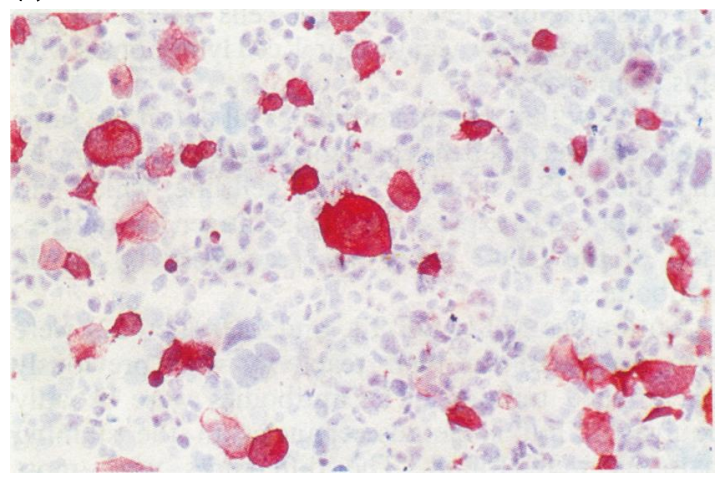

(11)

Fig 8 Reactive $T$ cells and macrophages in a case of B cell non-Hodgkin's lymphoma stained with DF-T1. Note lack of staining of the tumour cells.

Fig 9 Epithelioid giant cells in a case of B cell non-Hodgkin's lymphoma stained with DF-T1. Note positive reactive T cells and negative tumour cells in this case.

Fig 10 Blood smear from a case of B cell CLL. There is strong staining of all but one of the lymphocytes.

Fig 11 COS-7 cells transfected the CD43 gene, stained with antibody DF-T1, showing the intense labelling of a minority of the cells.

\section{Transfectants}

COS-7 cells transfected with the CD43 gene reacted strongly with DF-T1, MT1, and L60 (Leu-22) and also with antibodies known to recognise CD43 (84-3C1, G19-1, and G10-2) both by flow cytometry (data not shown) and by APAAP (fig 11). Control cells transfected with vector alone were unlabelled.

\section{Discussion}

Although antibody MT1 has been used by many laboratories to stain $T$ cells in paraffin wax sections, our report represents the first attempt to define its target molecule in human tissues. The data presented in this paper indicate that MT1 and also antibodies DF-T1 and L60 (Leu-22) all recognise a well defined molecule, the CD43 antigen, also known as sialophorin. The assignment of these antibodies to the
CD43 group rests on data obtained by independent techniques - that is, biochemical analysis; reactivity on tissue sections, cell smears and cell suspensions; and staining of cells transfected with the cloned CD43 gene.

Biochemical analysis by Western blotting showed that the antibodies react with molecules of identical weight, although there was clear variation between different sources of the antigen (range 95-160 kilodaltons). This heterogeneity should be borne in mind when comparing the biochemical data obtained in the present paper with those of previous studies. ${ }^{247}$ The diffuse appearance of the bands in polyacrylamide gels is consistent with the high degree of glycosylation of CD43. ${ }^{1025}$ This may be relevant to the suitability of these antibodies for use on routinely processed histological tissue sections, because other carbohydrate rich glycoproteins - CD15-for example, are known 
to be resistant to formalin fixation.

Equivalent results were obtained with MT1, DF-T1, L60 (Leu-22) and the three anti-CD43 antibodies when they were compared on normal tissue sections. The patterns of reactivity obtained in tissue sections with myeloid cells, T cells, and some B cell tumours is consistent with the limited data obtained by flow cytometry in the Third Workshop. ${ }^{7}$ Double staining experiments by flow cytometry showed that CD43 was also found on some non-malignant B cells, usually at lower levels than T cells. The demonstration of CD43 antigen on B cells at levels below the threshold of standard immunohistological staining of tissue sections may be relevant to the finding that some cases of B cell neoplasia are positive for the antigen. Similarly, the existence of a few normal $T$ cells which lack the CD43 antigen may account for $T$ cell lymphomas with this phenotype.

The view that the six antibodies all detect the same molecule was independently corroborated by showing that the COS-7 monkey kidney cell line, which had been induced to express the CD43 antigen by transfection of the CD43 gene, was recognised by all six antibodies.

Antibodies MT1, DF-T1, and L60 (Leu-22) were also compared for their reactivity with previously phenotyped tumours. The antibodies were broadly equivalent but some discrepancies in the staining patterns were found. The differences were most evident when staining B cell neoplasms on which the antigen, when present, is often only weakly expressed. Reports of the rate at which MT1 reacts with B cell tumours in paraffin wax sections show considerable differences, ranging from $0-49 \%$ (table 4 ), and variability in MT1 staining caused by differences in fixation time has been noted previously. ${ }^{32}$ These results suggest that technical variables, such as fixation, enzymatic digestion, and staining, or differences in antibody avidity may influence the threshold for positive staining in paraffin wax sections, particularly when the antigen is present at low concentrations. It is of relevance that no differences between the reactions of the antibodies MT1, DF-T1, and L60 (Leu-22) were seen on CLL blood smears (in which there was less possibility of fixation and processing artefacts). Thus even when it is clear from biochemical studies that antibodies recognise the same molecule, differences in the staining reactions in sections from the same tumour do occur.

The observation that the antigen recognised by the six antibodies is found on some B cell tumours is reminiscent of CD5 expression on B cell CLL and some B cell lymphomas. The mechanism of expression on B CLL cells, however, is likely to be different for CD5 and CD43 because cases of CLL were encountered in which either one of these antigens was found in the absence of the other.

In conclusion, the antibody MT1, widely used for detecting $T$ cells in paraffin wax sections, is not a unique reagent but belongs to the CD43 cluster first described in 1986. DF-T1 and L60 (Leu-22) also recognise the same molecule, and the three antibodies give broadly equivalent immunostaining on routinely processed tissue sections. It is clear that CD43 antigen is expressed on a proportion of B cell neoplasms, so that staining for this molecule, when phenotyping lymphoid proliferations, should always be accompanied by staining for other independent $T$ cell markers such as anti-CD $3^{33}$ and UCHL1. ${ }^{34}$ The findings of our paper should help to prevent pathologists inadvertently staining with two anti-CD43 antibodies in the belief that they are detecting different $\mathrm{T}$ associated antigens.

Anti-CD43 antibodies may also be of value in showing that a $\mathrm{T}$ cell proliferation is neoplastic, because of the non-reactivity of the T cells, as has been shown with antibody L60 (Leu-22). ${ }^{5}$ The same study also showed that the expression of CD43 on B cell proliferations correlated with malignancy.

Finally, the reactivity with myeloid cells may be of practical value in providing additional evidence that cells are of this lineage. An example of this application is to be found in the report by Facchetti $e t$ al,$^{35}$ that "plasmacytoid $\mathrm{T}$ cells" react with the anti-CD430 antibody MT1, but not with other anti- $\mathrm{T}$ cell reagents providing evidence for a myeloid rather than a $\mathrm{T}$ cel $\mathrm{B}$ origin.

KCG is a Wellcome Senior Research Fellow in clinical science. This work was supported by the Leukaemia Research Fund.

\section{References}

1 Mason DY, Gatter KC. The role of immunocytochemistry in diagnostic pathology. J Clin Pathol 1987;40:1042-54.

2 Poppema S, Hollema H, Visser L, Vos H. Monoclonal antibodies (MT1, MT2, MB1, MB2, MB3) reactive with leukocyte subsets in paraffin-embedded tissue sections. Am J Pathol 1987;127: 418-29.

3 Weiczorek R, Bindl J, Knowles DM. Monoclonal antibody L60 preferentially detects neoplastic $T$ cells in formalin-fixed, paraffin-embedded tissue sections. Chicago: United States and Canadian Academy of Pathologists, 1987:86.

4 Strickler JG, Weiss LM, Copenhaver CM, et al. Monoclonal antibodies reactive in routinely processed tissue sections of malignant lymphoma, with emphasis on $\mathrm{T}$-cell lymphomas. Hum Pathol 1987;18:808-14.

5 Picker LJ, Weiss LM, Medeiros LJ, Wood GS, Warnke RA. Immunophenotypic criteria for the diagnosis of non-Hodgkin's lymphoma. Am J Pathol 1987;128:181-201.

6 Hollema H, Poppema S. Immunophenotypes of malignant lymphoma centroblastic-centrocytic and malignant lymphoma centrocytic: an immunohistological study indicating a derivation from different stages of B cell differentiation. Hum Pathol 1988; 19:1053-9.

7 Cobbold S, Hale G, Waldmann H. Non-lineage, LFA-1, family, 
and leucocyte common antigens: new and previously defined clusters. In: McMichael, AJ, ed. Leucocyte typing III. White cell differentiation antigens. Oxford: Oxford University Press, 1987: 788-803.

8 Remold-O'Donnell E, Zimmerman C, Kenney D, Rosen FS. Expression on blood cells of sialophorin, the surface glycoprotein that is defective in Wiskott-Aldrich syndrome. Blood 1987;70:104-9.

9 Remold-O'Donnell E, Davis AE, Kenney D, Bhaskar KR, Rosen FS. Purification and chemical composition of $\mathrm{gpL} 115$, the human lymphocyte surface sialoglycoprotein that is defective in Wiskott-Aldrich syndrome. J Biol Chem 1986;261:7527-30.

10 Killeen N, Barclay AN, Willis AC, Williams AF. The sequence of rat leukosialin (W3/13 antigen) reveals a molecule with $\mathrm{O}$-linked glycosylation of one third of its extracellular amino acids. EMBO J 1987;6:4029-34.

11 Borche L, Lozano F, Vilella R, Vives J. CD43 monoclonal antibodies recognise the large sialoglycoprotein of human leukocytes. Eur J Immunol 1987;16:1523-6.

12 Mentzer SJ, Remold-O'Donnell E, Crimmins MAV, Bierer BE, Rosen FS, Burakoff SJ. Sialophorin, a surface sialoglycoprotein defective in the Wiskott-Aldrich syndrome, is involved in human T lymphocyte proliferation. J Exp Med 1987;165: 1383-92.

13 Bierer BE, Peterson A, Park J, et al. T cell activation: the T-cell erythrocyte receptor (CD2) and sialophorin (CD43). Immunology and Allergy Clinics of North America 1988;8:51-67.

14 Axelsson B, Youseffi-Etemad R, Hammarstrom S, Perlmann P. Induction of aggregation and enhancement of proliferation and IL- 2 secretion in human T cells by human $T$ cells by antibodies to CD43. J Immunol 1988;141:2912-17.

15 Pharmacia Laboratory Separation Division. Specific monoclonal antibody purification techniques. 1986;May:1-3.

16 Collins SJ, Gallo RC, Gallager RE. Continuous growth and differentiation of human myeloid leukemia cells in suspension culture. Nature 1977;270:347-8.

17 Koeffler HP, Golde DW. Acute myelogenous leukaemia: A human cell line responsive to colony stimulating activity. Science 1978;200:1153-4.

18 Gluzman Y. SV40-Transformed simian cells support the replication of early SV40 mutants. Cell 1981;23:175-82.

19 Seed B. An LFA-3 cDNA encodes a phospholipid-linked membrane protein homologous to its receptor CD2. Nature 1987; 329:840-2.

20 Seed B, Aruffo A. Molecular cloning of the CD2 antigen, the T-cell erythrocyte receptor, by a rapid immunoselection procedure. Proc Natl Acad Sci USA 1987;84:3365-9.

21 Stross WP, Jones M, Mason DY. Automation of the APAAP immunocytochemical technique. J Clin Pathol 1989;42:106-12.

22 Cordell JL, Falini B, Erber WN, et al. Immunoenzymatic labelling of monoclonal antibodies using immune complexes of alkaline phosphatase and monoclonal anti-alkaline phosphatase (APAAP complexes). J Histochem Cytochem 1984;32:219-29.

23 Laemmli UK. Cleavage of structural proteins during the assembly of the head of bacteriophage T4. Nature 1970;227:680-5.

24 Towbin H, Staehelin T, Gordon J. Electrophoretic transfer of proteins from polyacrylamide gels to nitrocellulose sheets: procedure and some applications. Proc Natl Acad Sci USA 1979;76:4350-4.

25 Remold-O'Donnell E, Kenney D, Rosen FS. Biosynthesis of human sialophorins and analysis of the polypeptide core. Biochemistry 1987;26:3908-13.

$26 \mathrm{Ng} \mathrm{CS}$, Chan JKC, Hui PK, Lo STH. Monoclonal antibodies reactive with normal and neoplastic $T$ cells in paraffin sections. Hum Pathol 1988;19:295-303.

27 Norton AJ, Isaacson PG. An immunocytochemical study of T-cell lymphomas using monoclonal and polyclonal antibodies effective in routinely fixed wax embedded tissues. Histopathology 1986; 10:1243-60.

28 Norton AJ, Isaacson PG. Detailed phenotypic analysis of B-cell lymphoma using a panel of antibodies reactive in routinely fixed wax-embedded tissue. Am J Pathol 1987;128:225-40.

29 Dobson CM, Myskow MW, Krajewski AS, Carpenter FH, Horne CHW. Immunohistochemical staining of non-Hodgkin's lymphoma in paraffin sections using the MB1 and MT1 monoclonal antibodies. J Pathol 1987;153:203-12.

30 Hall PA, D'Ardenne AJ, Butler MG, Habeshaw JB, Stansfeld AG New marker of B lymphocytes, MB2: comparison with other lymphocyte subset markers active in conventionally processed tissue sections. J Clin Pathol 1987;40:151-7.

31 West KP, Warford A, Fray L, Allen M, Campbell AC, Lauder I. The demonstration of B-cell, T-cell and myeloid antigens in paraffin sections. J Pathol 1986;150:89-101.

32 Ngan BY, Picker LJ, Medeiros LJ, Warnke RA. Immunophenotypic diagnosis of non-Hodgkin's lymphoma in paraffin sections: Coexpression of L60 (Leu22) and L26 antigens correlates with malignant histologic findings. Am J Clin Pathol 1989; 91:579-83.

33 Mason DY, Krissansen GW, Davey FR, Crumpton MJ, Gatter KC. Antisera against epitopes resistant to denaturation on T3 (CD3) antigen can detect reactive and neoplastic $T$ cells in paraffin embedded tissue biopsy specimens. J Clin Pharmacol 1988;41:121-7.

34 Smith SH, Brown MH, Rowe D, Callard RE, Beverley PCL. Functional subsets of human helper-inducer cells defined by a new monoclonal antibody, UCHL1. Immunology 1986;58: 63-70.

35 Facchetti F, De Wolf-Peeters C, Van den Oord JJ, De Vos R, Desmet V. Plasmacytoid T cells: a cell population normally present in the reactive lymph node. An immunohistochemical and electron microscopic study. Hum Pathol 1988;19:1085-92.

36 Said JW, Stoll PN, Shintaku P, Bindl JM, Butmarc JR, Pinkus GS Leu-22: a preferential marker for $T$-lymphocytes in paraffin sections. Am J Clin Pathol 1989;91:542-9.

Requests for reprints to: Dr WP Stross, Nuffield Department of Pathology, University of Oxford, John Radcliffe Hospital, Headington, Oxford OX3 9DU, England. 